\title{
Transport properties of chitosan membranes for zinc (II) removal from aqueous systems
}

Article in Separation and Purification Technology · February 2017

DOI: 10.1016/j.seppur.2017.02.030

CITATIONS

0

4 authors, including:

\section{Peter Osifo}

Vaal University of Technology

17 PUBLICATIONS 228 CITATIONS

SEE PROFILE

\section{David J. Branken}

North West University South Africa

18 PUBLICATIONS 33 CITATIONS

SEE PROFILE
READS

20

Some of the authors of this publication are also working on these related projects:

Project
Chromium (VI) ion adsorption by grafted cross-linked chitosan beads in aqueous solution-A mathematical and statistical modelling study View project

Separation of nitrogen trifluoride and tetrafluoromethane View project

All content following this page was uploaded by David J. Branken on 20 February 2017. 


\section{Accepted Manuscript}

Transport properties of chitosan membranes for zinc (II) removal from aqueous systems

Peter O Osifo, Hein W.J.P. Neomagus, Hein van der Merwe, David J Branken

PII:

$$
\text { S1383-5866(16)30689-X }
$$

DOI: http://dx.doi.org/10.1016/j.seppur.2017.02.030

Reference: SEPPUR 13561

To appear in:

Separation and Purification Technology

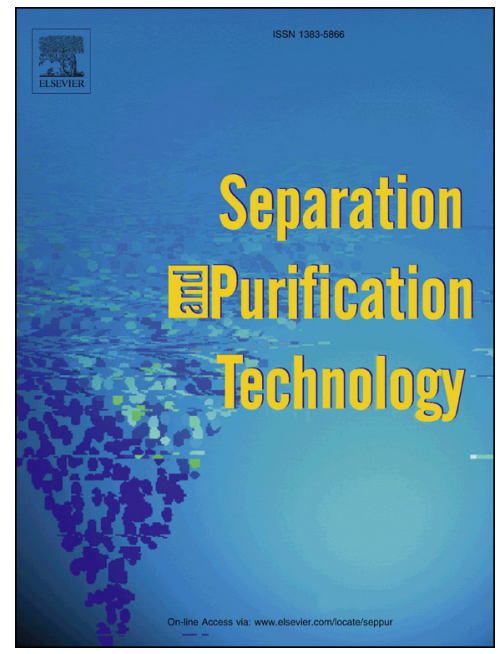

Received Date: $\quad 9$ June 2016

Revised Date: $\quad 19$ January 2017

Accepted Date: $\quad 13$ February 2017

Please cite this article as: P.O. Osifo, H.W.J. Neomagus, H. van der Merwe, D.J. Branken, Transport properties of chitosan membranes for zinc (II) removal from aqueous systems, Separation and Purification Technology (2017), doi: http://dx.doi.org/10.1016/j.seppur.2017.02.030

This is a PDF file of an unedited manuscript that has been accepted for publication. As a service to our customers we are providing this early version of the manuscript. The manuscript will undergo copyediting, typesetting, and review of the resulting proof before it is published in its final form. Please note that during the production process errors may be discovered which could affect the content, and all legal disclaimers that apply to the journal pertain. 


\title{
Transport properties of chitosan membranes for zinc (II) removal from aqueous systems
}

\author{
Peter O Osifo $^{\mathrm{a} 1}$, Hein WJP Neomagus ${ }^{\mathrm{b}}$ Hein van der Merwe ${ }^{\mathrm{a}}$, David J Branken ${ }^{\mathrm{b}}$ \\ ${ }^{a}$ Department of Chemical Engineering, Vaal University of Technology, P/Bag X021, Vanderbijlpark 1900, RSA. \\ ${ }^{\mathrm{b}}$ School of Chemical and Minerals Engineering, North-West University, P/Bag X6001, Potchefstroom 2520, RSA.
}

\begin{abstract}
Chitosan materials that were prepared from different sources of fishery waste were subsequently characterized, and the influence of molecular weight and degree of deacetylation (DDA) on the chitosan-acetic acid solution viscosity was studied. The molecular weight of the prepared chitosan was found to influence the viscosity of the solution, and more specifically it was found that an increase in molecular weight resulted in a higher chitosan-acetic acid solution viscosity, while the DDA was found not to influence the viscosity of chitosan-acetic solutions. Chitosan solutions with varying concentrations, and thereby also varying viscosities, were used to produce chitosan membranes by the phase inversion technique, followed by cross-linking the membranes using glutaraldehyde. The chitosan content of the membranes was found to be only 4-6 mol\%, and the characterisation results indicated that the membranes could be visualised as consisting of a hydrated polymeric network in which chitosan forms a rigid honeycomb structure. The moisture that was present in the membrane was found to be present as fixed water, integrated with the chitosan that enabled the use of a pressure driving force for the removal of moisture from the membrane. The free water content was subsequently found to be equal to the porosity of the membrane, namely $65 \%$ of the total water in the membrane, with $30 \%$ of the water being characterised as fixed water. The membrane wet density, pore radius and specific surface area were determined as $1100 \mathrm{~kg} \cdot \mathrm{m}^{-3}, 40 \mathrm{~nm}$, and $1.15 \times 10^{5} \mathrm{~m}^{2} \mathrm{~kg}^{-1}$ respectively. Subsequently, the chitosan membranes were found to be analogous in their transport behaviour to ultrafiltration membranes. The pure water flux of the membranes was found to be in the order of $12 \mathrm{Lm}^{-2} \mathrm{hr}^{-1} \mathrm{bar}^{-1}$, and the transport of solutes and solvent could be modelled sufficiently at low solute concentrations using a generic membrane model derived from irreversible thermodynamics.
\end{abstract}

Keywords: Chitosan membrane, zinc adsorption, porosity, specific surface area, viscosity.

${ }^{1}$ Corresponding author. Tel.:+27-16-9509599; fax: +27-16-9509796.

E-mail address: petero@vut.ac.za 


\section{Introduction}

Chitosan is a biopolymer material that can be used for the removal heavy metals from wastewater effluents. This aspect makes it an attractive material for water purification applications since it possesses a high affinity for heavy metal species that are present in water and wastewater [1]. Other than a high heavy metal adsorption capacity, other advantages that chitosan adsorbents have over other low-cost adsorbents such as marine algae, peat, pecan shells, and corn cobs are that; (1) it can be obtained cheaply in large quantity from fishery wastes of crustaceans such as crabs, lobsters and krill, and (2) it can be transformed into dry flakes and gels [1-8]. The gel form can be moulded into different configurations depending on the end uses. One such configuration is chitosan gel beads that have been widely reported in water treatment applications, and that have also been used in drug delivery medicinal applications [1_3]. Another form, gel-type membranes is not frequently studied, perhaps, due to lack of essential information regarding its transport properties [3;7-9].

Several studies of chitosan membranes are mainly focused on the adsorption characteristics of chitosan membranes $[10 ; 11]$ but in this study, their transport properties are described. For the purpose of this study, the transport of pure water and zinc-ions through chitosan membranes have been investigated, as knowledge of such transport mechanisms and properties are essential for design purposes, and for assessing the efficiency of membrane cleaning procedures [12]. The driving force that is necessary for transport to occur through membranes can be affected by several conditions of pressure, concentration, electropotential, $\mathrm{pH}$ of solution, temperature difference or a combination of these. Pressure-driven membrane processes can be classified according to the applied pressure difference, flux and (average) pore size. Chitosan membranes can be regarded as being porous membranes; and therefore transport modelling should be done in accordance with pressure-driven membrane processes.

\section{Materials and methods}

\subsection{Chitosan preparation}

It has been reported that chitosan from different sources have varying characteristics, and that the viscosity of a chitosan solution is influenced by the chitosan concentration [13;14]. To obtain chitosan of low to medium molecular weight for use in this work, a variety of chitosan feedstock materials from various sources were used to prepare different types of chitosan as summarised below:

Chitosan A: Cape rock lobster shells were collected in the surroundings of Cape Town, South Africa and were used as raw material to produce chitin that were converted into chitosan flakes.

Chitosan B: Industrial grade chitin flakes (obtained from crab shells) was purchased from SIGMA (Cat. No. 41795-5) and was converted into chitosan flakes. 
Chitosan C: Chitosan flakes produced from a mixture of lobster $(10 \%)$, crab $(2 \%)$ and prawn shells (88\%) that were disposed from a South African restaurant (Rio del Sol, Vanderbijlpark, South Africa).

Chitosan D: Commercial grade, low molecular weight chitosan purchased from SIGMA (Cat. No. 41796-1).

Chitosan F: $\quad$ Commercial grade, high molecular weight chitosan purchased from SIGMA (Cat. No. 41796-3).

In this work, the shells were crushed (1-5 mm diameter) and used to prepare chitin flakes, and subsequently chitosan flakes according to the method described in detail by No and Meyer in the Chitin Handbook [15].

\subsection{Determination of chitosan DDA and molecular weight}

The molecular weight and the DDA of the synthesised chitosan samples were determined using the infrared spectroscopy (IR) method as described by Snyman et at. [16] and Robert [17]. Specifically, the pellet method was used for analysing samples with a Nicolet MAGNA-IR 550 Spectrometer Series II Fourier-transform infrared analyser. A Size exclusion chromatography/Multiple Angle Laser Light Scattering (SEC/MALLS) technique was used to characterise the molecular weight of the various chitosan samples using TSK GW columns with an on-line double detection system including a Waters R410 differential refractometer and a Dawn Wyatt multiangle laser light scattering photometer.

\subsection{Chitosan viscosity measurements and membrane preparation}

During preparation of chitosan membranes, the viscosity of the chitosan solutions is of particular importance [14;18]. Hence, the influence of the chitosan molecular weight and DDA on the viscosity of chitosan solutions were determined using the prepared chitosan samples A, B, C, D, D, and F. Mixtures of 7 wt. \% chitosan and 4 wt.\% aqueous acetic acid solutions were agitated using a magnetic stirrer and the viscosity of the various chitosan solutions were determined after the complete dissolution of the chitosan using an Ostwald Viscometer [19]. The temperature was kept constant at $25^{\circ} \mathrm{C}$ during the viscosity measurements.

The process variables for manufacturing chitosan membrane (chitosan-, acetic acid- and sodium hydroxide concentration) were also varied. The membranes were produced using a phase inversion method as described by Kaminski and Modrzejewska [20]. This method has been used in several other studies (e.g. Guibal et al. [21]; Kawamura et al. [22]; Osifo et al. [23]) to produce chitosan beads, but was adapted here to produce flat sheet membranes. The viscous chitosan solutions, produced from the mixture of dissolved chitosan and acetic acid, were poured into a mould that was 
placed on a flat glass surface. The glass plate, including the mould and chitosan solutions were carefully lowered into an aqueous solution of sodium hydroxide (varied between 1 and 9 wt.\%, 97\% pure, supplied by Saarchem Ltd) and left undisturbed for 15 minutes at a constant temperature of 25 ${ }^{\circ} \mathrm{C}$. After the membranes were formed, they were washed, using flowing de-ionised $\left(<0.5 \mu \mathrm{Scm}^{-1}\right)$ water for 2 minutes, and the membranes and the mould were removed from the glass plate. The membrane was then removed from the mould and soaked in de-ionised water for 1 hour. After soaking, the membranes were washed once again using de-ionised water until the washing water had a neutral $\mathrm{pH}$. Throughout the membrane manufacturing process, the ambient temperature was kept constant at $25( \pm 1){ }^{\circ} \mathrm{C}$. The disk shaped membranes had average thicknesses of $0.8 \mathrm{~mm}$ and an average diameter of $47 \mathrm{~mm}$.

To prevent chitosan membrane dissolution in acidic media, the membranes were cross-linked according to the procedure described by Guibal et al. [21]. Accordingly, the membranes were crosslinked by submersion in a 2.5 wt.\% solution of glutaraldehyde ( $25 \%$ pure supplied by Merck) at 25 ${ }^{\circ} \mathrm{C}$. A volume of $1.5 \mathrm{~cm}^{3}$ glutaraldehyde solution per gram of wet membrane was used. After crosslinking, the membranes were washed thoroughly to remove all the glutaraldehyde.

\subsection{Determination of wet membrane density}

The wet membrane density of the membranes was determined using the method of Kawamura et al. [22]. The excess cohesive water was removed from the membranes before weighing, and the volume of the disk shaped membranes were determined from the membrane diameter and thickness. Finally, the density was calculated using Eq. (1):

$$
\rho_{\mathrm{wm}}=\frac{m_{w m}}{V_{w m}}
$$

where $\mathrm{m}_{\mathrm{wm}}$ and $\mathrm{V}_{\mathrm{wm}}$ are the mass of wet membrane in $\mathrm{kg}$ and volume of wet membrane in $\mathrm{m}^{3}$ respectively.

\subsection{Determination of membrane porosity}

Chitosan membranes are gel-type membranes and are generally classified as being non-porous membranes. However, tiny pores are present on a molecular level in non-porous membranes. The membrane porosity was determined using the method reported by Kawamura et al. [22]. In this method, it is assumed that the porosity equals the free volume and it is the volume of water in the membrane that is not fixed to (adsorbed onto) the membrane matrix. This free water can be removed easily by mechanical forces. By spinning a wet membrane in a centrifuge (Sorval Instrument, Model: 
$\mathrm{RC} 5 \mathrm{C})$ at $1000 \mathrm{rpm}$ at room temperature for 2 minutes, followed by collection and weighing of the released free water. The fractional free volume was subsequently determined using Eq. (2):

$$
\varepsilon=\frac{\mathrm{V}_{\mathrm{fwp}}}{\mathrm{V}_{\mathrm{wm}}}
$$

where $\varepsilon$ is the porosity (fraction free water volume) in $\mathrm{m}^{3} \mathrm{~m}^{-3}, \mathrm{~V}_{\mathrm{fwp}}$ is the volume of free water in the membrane pores in $\mathrm{m}^{3}$, and $\mathrm{V}_{\mathrm{wm}}$ is the wet membrane volume in $\mathrm{m}^{3}$.

\subsection{Determination of maximum pore radius}

The maximum pore radius of the membranes were determined using the Bubble-point method as described by Pellegrin et al. [24]. This method is based on measuring the minimum pressure required for gas permeation through a water-filled membrane. In this way, the maximum pore radius can be determined using the Young equation [Eq. (3)]:

$$
r_{P}=\frac{2 \cdot \gamma}{\Delta P} \cdot \cos \theta
$$

In Eq. (3), $\theta$ (contact angle between a water drop and the membrane surface (rad)) is zero, since the radius of the gas bubble is equal to the pore radius at the point of where it completely penetrated the membrane. $r_{\mathrm{P}}$ is the pore radius in the membrane in $\mathrm{nm}, \Delta \mathrm{P}$ is the pressure difference in $\mathrm{Pa}$ where the first bubble is observed, and $\gamma$ is the Surface tension $\mathrm{Nm}^{-1}$.

\subsection{Determination of the specific surface area}

The specific surface area of the dried membrane was determined using the iodine adsorption number as described by Pawlowski [25]. In this method, the amount of iodine adsorbed by the dry membrane is measured according to the difference in iodine concentration before and after adsorption, whereby the iodine concentration is determined by titration using a sodium thiosulphate solution. The amount of adsorbed iodine per gram adsorbent (chitosan) is then correlated to the surface area as described by Pawlowski [25].

\subsection{Scanning Electron Microscopy (SEM) analyses}

Scanning Electron Microscopy (SEM) analyses were performed according to the description of Osifo and Masala [26]. Chitosan membranes were dried and the solid structure was examined using a FEI Quanta 200 ESEM instrument, of which the resolution was about 10 nanometers. The following steps were followed during sample preparation prior to the SEM analyses: 
(a) As a result of large amount of water in the specimen, evaporation of water would have caused problems when exposed to the high vacuum of the SEM analysis chamber. Therefore, the sample needed to be dehydrated, which it was done by submerging membrane samples for short periods of time in series of ethanol solutions of which the concentrations were gradually increased.

(b) The samples were then further dried in a supercritical $\mathrm{CO}_{2}$ atmosphere.

(c) The samples were then directly mounted onto the sample stub of the SEM instrument using double-sided carbon tape.

(d) The specimen was sputter-coated with a gold conductive layer to increase the conductivity. This is necessary to reduce thermal damage, and to increase the electron emission and mechanical stability.

\subsection{Membrane permeability}

The permeability through the membranes was measured for water and solutions with varying heavy metal $(\mathrm{Zn}(\mathrm{II}))$ concentrations, prepared from analytical grade $\mathrm{ZnSO}_{4} \cdot 7 \mathrm{H}_{2} \mathrm{O}$ ( $99 \%$ pure, supplied by Merck) in de-ionised water (conductivity $<0.5 \mu \mathrm{Scm}^{-1}$ ) using a dead-end membrane module that was purchased from Milipore (Figure 1). The membrane module consisted of a sintered stainless steel support, with an average mesh size of $0.1 \mathrm{~mm}$, and the transport resistance of the support was negligible when compared to the chitosan membrane, since the pore size of the support was at least three orders of magnitude larger than that of the membranes.

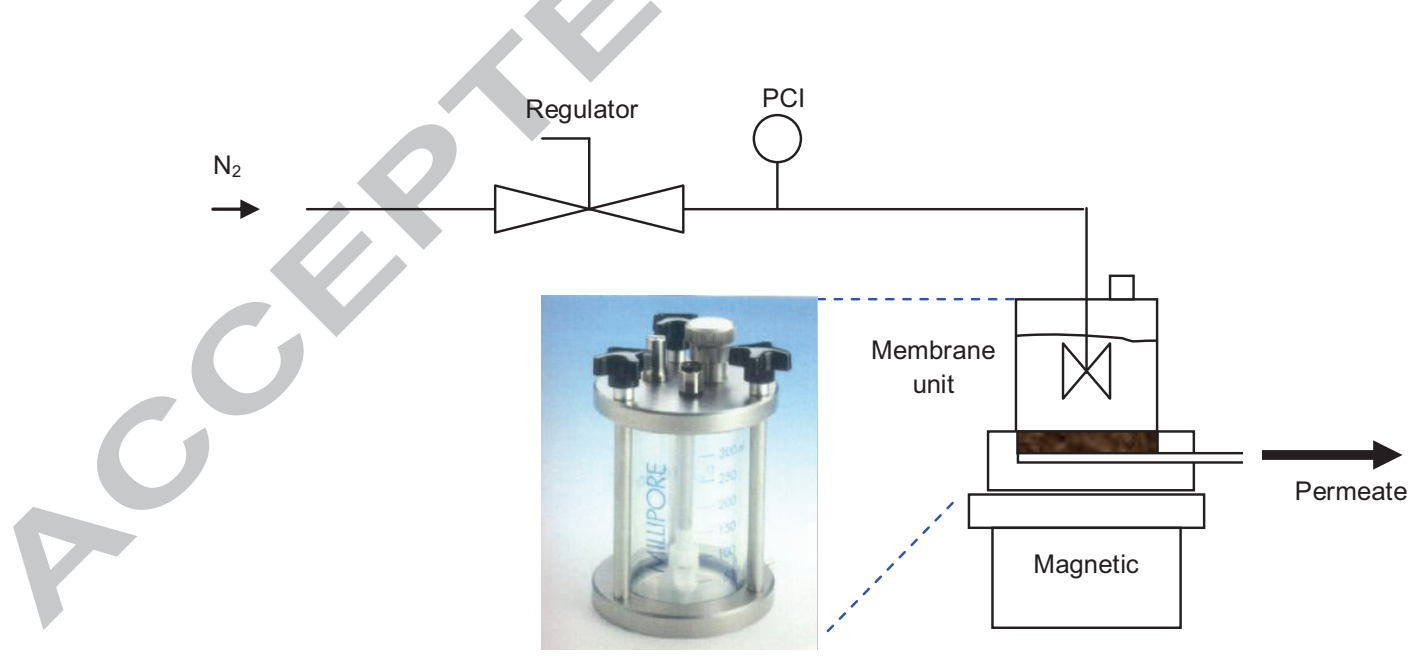

Figure 1: Liquid flux set-up for permeability studies.

The $\mathrm{pH}$ of the zinc solution was controlled at a $\mathrm{pH}$ of 5, using dilute sulphuric acid (from 98\% pure supplied by Saarchem Ltd) and dilute sodium hydroxide (from 97\% pure supplied by Saarchem Ltd) 
and a Jenway $3310 \mathrm{pH}$ meter. The membrane was clamped in the membrane holder and the zinc solution was allowed to permeate through the membranes at $25^{\circ} \mathrm{C}$ under varying feed pressure, while the temperature was controlled using a hot plate (Hydolph MR2002). The water or zinc solution was poured into the membrane holder, and the temperature was monitored until a constant temperature was obtained. Subsequently, the permeability (or flux) was measured under a $50 \mathrm{kPa}$ pressure difference. The pressure difference was applied to the cell using pressurised nitrogen. To ensure measurements of the steady-state transport properties, one litre $(1 \mathrm{~L})$ of the different zinc solutions were permeated through the membranes until equilibrium was reached w.r.t. the zinc concentration of the permeate, i.e. the $\mathrm{Zn}(\mathrm{II})$ concentration remained constant. The permeate $\mathrm{Zn}$ (II) concentration was monitored by quantitative analysis of the zinc ion concentration present in the filtrate using Atomic Absorption Spectrophotometric analysis with a Perkin Elmer, Analyst 200 Model B3150070.

The flux is expressed as the volume flow through the membrane, per unit area and time [Eq. (4)]:

$$
J_{V}=\frac{V}{A \cdot t}
$$

where $J_{v}$ is the flux in L. $\mathrm{m}^{-2} \cdot \mathrm{hr}^{-1}, V$ is the volume of liquid in $\mathrm{m}^{3}$ that was collected in time $t(\mathrm{~s})$, and A is the membrane surface area in $\mathrm{m}^{2}$.

\subsection{Membrane Transport Model}

\subsubsection{Solvent and solute Flux}

The permeability coefficient related to the transport of molecules can be expressed in various ways, based on the structural properties of the membrane. Chitosan membranes are not exactly similar to "traditional" membranes (membranes in which solutes or particles are rejected due to size exclusion or repulsion), and can be modelled as gel-type membranes [27-29]. In modelling transport through gels, two approaches are presented in the literature: the free volume model and the capillary pore model [29]. In the free volume model, the membrane is assumed to consist of a homogenous hydrated network. The diffusive transport of solutes occurs through the water-filled volumes of the network by successive jumps through the pores (free water volume elements) that are larger than the permeating solute, and these spaces are not fixed in size and location. The effective total pore volume for solute diffusion therefore corresponds with the free water volume in the membrane [30]. By contrast, the membrane is visualised as having fixed pores with uniform radii in the capillary pore model, and transport is regarded to occur through convective transport, similar to that of porous membranes. In this study, although being gel-type membranes, the chitosan membranes were classified as being porous membranes.

Different transport models have been developed to quantify the permeability coefficient $\left(L_{P}\right)$ of porous membranes in terms of the (average) pore size, porosity and tortuosity. Membranes consisting 
of a sponge-like structure are typical of organic membranes produced by the phase inversion technique. These membranes can best be described either by the Kozeny-Carman equation [Eq. (5)], or the Hagen-Poiseuille equation [Eq. (6)] [30;31]:

$$
\begin{aligned}
& L_{p}=\frac{\varepsilon^{3}}{K \cdot \mu \cdot S_{o}^{2} \cdot(1-\varepsilon)^{2} \cdot x} \\
& L_{p}=\frac{\varepsilon \cdot r_{P}^{2}}{8 \cdot \mu \cdot \tau \cdot x}
\end{aligned}
$$

In this study, it was concluded that the pores are filled with free water, and that the free water elements in which the free water resided could be viewed as open pores through which water is transported. Therefore, the fractional free water-volume is equivalent to the porosity $(\varepsilon)$ of the membrane. The other parameters are namely: the liquid viscosity in $\mathrm{Pa}-\mathrm{s}(\mu)$, the tortuosity $(\tau)$, the membrane thickness in $\mathrm{m}(x)$, the membrane surface area in $\mathrm{m}^{2}\left(\mathrm{~S}_{\mathrm{o}}\right)$, the membrane pore radius in $\mathrm{m}$ $\left(\mathrm{r}_{\mathrm{p}}\right)$, and a constant $(\mathrm{K})$ that depends on the porosity and membrane size and shape.

By disregarding the structural characteristics of the membrane, the transport through the membrane can be described through the laws of irreversible thermodynamics, where the solvent flux, $J_{v}$, and the solute flux, $J_{s}$, can be expressed by Eqs. (7) and (8) respectively [32]:

$$
\begin{aligned}
& J_{V}=L_{P} \cdot(\Delta P-\sigma \cdot \Delta \pi) \\
& J_{S}=c_{S} \cdot(1-\sigma) \cdot J_{V}+\omega \cdot \Delta \pi
\end{aligned}
$$

where $\Delta P$ is pressure drop applied across the membrane in bar, $L_{p}$ is the membrane permeability in L. $\mathrm{m}^{-2} \cdot \mathrm{hr}^{-1} \cdot \mathrm{bar}^{-1}, \Delta \pi$ is the osmotic pressure difference in bar, and $C_{s}$ is the solute concentration in mg. $L^{-1}$. In this thermodynamic model, which does not take the mechanism of transport into account, the transport is described by three parameters, namely the reflection coefficient $(\sigma)$, which is a measure of the separation efficiency of the membrane $(\sigma=0$ means no separation, while $\sigma=1$ represents an ideal separation); and $L_{p}$ and $\omega$, which are measures of respectively the solvent and solute permeability. Normally, the osmotic pressure difference $(\Delta \pi)$ in ultrafiltration processes is negligibly small, but should be taken into account for the application of zinc removal with chitosan membranes at high feed concentrations, since the osmotic pressure increases with solute concentration. When the solute is not completely retained by the membrane then the osmotic pressure difference is not equal to $\Delta \pi$, but equal to $\sigma \cdot(\Delta \pi)$.

This thermodynamic model therefore contains three model parameters that can be obtained from a fit to the experimental data. For pure water the osmotic pressure, $\Delta \pi=0$, and Eq. (7) reduces to Eq. (9), whereby the solvent flux can be expressed in terms of the permeability coefficient $\left(L_{p}\right)$ only: 


$$
\mathrm{J}_{\mathrm{V}}=\mathrm{L}_{\mathrm{P}} \cdot \Delta \mathrm{P}
$$

Since $L_{P}$ can therefore be determined independently, $\sigma$ and $\omega$ can be evaluated using Eqs. (7) and (8) for experiments with varying salt concentrations, as was done in this study.

The transport model equations Eqs. (5) - (9) were therefore used in this study to model the transport of water as solvent, and $\mathrm{Zn}$ (II) as the solute through the chitosan membranes, and the results from the various models are compared in Section 3.

\subsubsection{Concentration Polarisation}

One of the general disadvantages of membrane processes is the occurrence of concentration polarisation. This phenomenon normally results in a significant decline in flux over time, and is more severe for ultra and nano-filtration than in other membrane processes. The process of concentration polarisation can occur when a solution is transported through a membrane and while the solvent freely permeates through the membrane the solute accumulates at the membrane-solution interface. Therefore, the concentration of the solute is larger at the membrane interface than in the bulk solution.

This concentration gradient causes a diffusive transport of the solute back to the bulk solution, and under steady state operation this diffusive transport, can in severe cases, equal the convective transport of the solute through the membrane [32,33]. In the case of relatively low solute concentration and pressure gradients (low solvent flux), the transport is not affected by concentration polarisation. However, at high solute concentrations and pressure gradients, it can play an important role and even have a controlling effect on the transport rate.

In a case where concentration polarisation completely determines the transport rate, the flux is independent of the pressure difference and is termed the limiting flux $\left(J_{\text {Vim }}\right)$, which can be calculated using Eq. (10) [34]:

$$
\mathrm{J}_{\mathrm{Vlim}}=\mathrm{k} \cdot \ln \left(\frac{\mathrm{C}_{\mathrm{m}}}{\mathrm{C}_{\mathrm{in}}}\right)
$$

where $\mathrm{c}_{\mathrm{in}}$ and $\mathrm{c}_{\mathrm{m}}$ are the solute concentrations in the bulk and at the membrane interface respectively (mg. $\left.\mathrm{L}^{-1}\right)$; $\mathrm{k}$ is the external mass transfer coefficient in the liquid $\left(\mathrm{L} \cdot \mathrm{m}^{-2} \cdot \mathrm{hr}^{-1}\right)$. Eq. (10) can also be written in linear form as shown in Eq. (11), which can be used together with experimental data to determine $\mathrm{c}_{\mathrm{m}}$ and $\mathrm{k}$.

$$
\mathrm{J}_{\mathrm{Vlim}}=\mathrm{k} \cdot \ln \mathrm{c}_{\mathrm{m}}-\mathrm{k} \cdot \ln \mathrm{c}_{\mathrm{in}}
$$




\section{Results and discussion}

\subsection{Molecular weight and DDA}

The DDA and molecular weight results are reported in in Table 1. Chitin was produced from the fishery waste (chitin $\mathrm{A}$ and $\mathrm{C}$ ) at a yield of $26 \%$, and the associated chitosan was subsequently produced from the chitin at a yield of $18 \%$. The average size of the chitosan A and C flakes was 1.5 $\mathrm{mm}$. The three different locally produced chitosan batches (A, B and C) were compared in terms of the DDA and molecular weight to the commercially available chitosan (D: Low molecular weight chitosan (Cat. No. 41796-1), E: High molecular weight chitosan (Cat. No. 41796-5) and F: Industrial grade chitosan (Cat. No. 41796-3), all purchased from SIGMA). From the results presented in Table 1 it is clear that the molecular weight of the chitosan depends on the source of the raw material (Chitin), while the DDA was comparable for the different sources. This can be related to the conditions under which chitosan preparation was performed. The chitosan A, B and C have a degree of deacetylation of $80( \pm 3) \mathrm{mol} \%, 78( \pm 3) \mathrm{mol} \%$ and $79( \pm 3)$ mol\% respectively, after a deacetylation period of six hours. Comparing the results with the commercially available chitosan, it can be concluded that chitosan A has the highest degree of similarity to the industrial grade chitosan D and F.

Table 1: Parameters of chitosan materials; molecular weight and DDA.

\begin{tabular}{|c|c|c|c|c|c|}
\hline & & Produced anc & Irchased chitc & & \\
\hline Characteristics & Chitosan B & Chitosan C & Chitosan D & Chitosan E & Chitosan F \\
\hline $\mathrm{Mw}\left(\mathrm{kg} \cdot \mathrm{kmol}^{-1}\right)$ & $\begin{array}{l}298900 \\
( \pm 4 \%)\end{array}$ & $\begin{array}{l}201300 \\
( \pm 4 \%)\end{array}$ & $60000 *$ & $400000 *$ & $150000 *$ \\
\hline DDA (\%) & $78( \pm 3)$ & $79( \pm 3)$ & $>98^{*}$ & $>98^{*}$ & $>98^{*}$ \\
\hline
\end{tabular}

The effect of DDA and molecular weight on chitosan solution viscosity is shown in Figure 2, from which it is clear that the viscosity increases with an increase of the molecular weight of the chitosan used to prepare the individual chitosan/acetic acid solutions. Chitosan A and Chitosan $\mathrm{F}$ had comparable molecular weights and a DDA, yet it is clear from Figure 2 that the viscosity in solution differed significantly. The effect of the degree of deacetylation on the viscosity is not significant, as reported by Muzzarelli [13], and due to the lack of a more comprehensive data set it is concluded that the viscosity is mostly influenced by the molecular weight of the chitosan, since the viscosity of the solutions increased more or less linearly with increasing molecular weight as also noted by Collins [35]. Since chitosan A was characterised by a relatively low molecular weight that yielded less viscous solutions, higher chitosan concentrations could be used for the subsequent membrane 
preparation that enabled higher adsorption capacities to be obtained. As noted by Wu et al. [14] the chitosan solution viscosity is crucial for the preparation of high quality membranes, since too high viscosities results in the formation of membranes that are characterised by significant defects due to the formation of cracks. Therefore, chitosan A was selected for the membrane preparation since it would allow higher adsorption capacities, while favourable solution viscosity was retained.

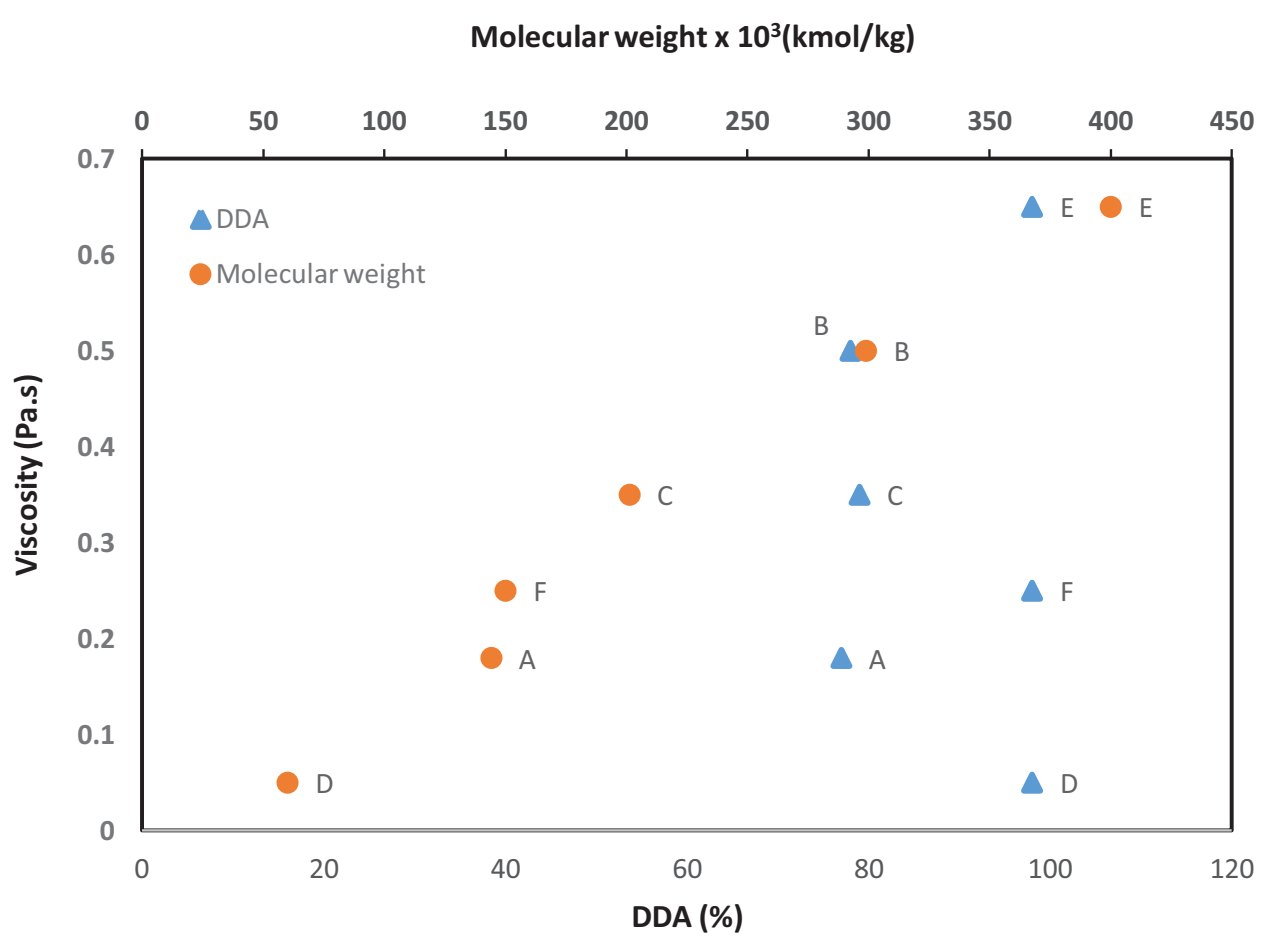

Figure 2: The effect of DDA and molecular weight on chitosan solution viscosity determined using $7 \%$ chitosan in $4 \%$ acetic acid at $25^{\circ} \mathrm{C}$.

In this work it was further found that in addition to the molecular weight, only changes in the chitosan concentration had a significant influence on the viscosity of the casting solutions, and that the other solution parameters, namely the changes in acetic acid and sodium hydroxide solution concentrations did not affect the viscosity of the casting solutions.

\subsection{Membrane Characterization}

The various properties of the resulting membranes are represented as a function of the chitosan concentration used in the $4 \mathrm{wt} . \%$ acetic acid casting solutions in Table 2 . It is clear that that the mass fraction of chitosan $\left(x_{\mathrm{c}}\right)$ in the membranes increased with increasing chitosan concentration of the casting solution. It is therefore evident that the membranes had a high water content that ranged 
between 95 and 98 wt.\%), which are in good agreement with the values obtained by Kawamura et al. [22]. The wet membrane density is a specific property of gel-type membranes, since it is directly related to membrane properties such as porosity and thus will influence the the transport properties of the membrane [22]. The values of wet membrane density (column 3) is represented as a function of the chitosan solution concentration, and it is clear that the wet density slightly increases with an increase in the chitosan concentration. As expected, only a slight change in density is observed when the chitosan concentration of the casting solution is increased since approximately $95 \mathrm{wt} . \%$ of the resulting membranes consisted of water. Since the increase in the wet membrane density is a result of higher chitosan concentrations, a slight decrease in porosity is also expected as shown in column 4 of Table 2, which was also observed by Kawamura et al. [22].

Table 2: The properties of chitosan membrane that was prepared from different mass fraction of chitosan in 4 wt. $\%$ acetic acid, $5 \% \mathrm{NaOH}$ and $25^{\circ} \mathrm{C}$.

\begin{tabular}{cccccc}
\hline $\begin{array}{c}(1) \\
\begin{array}{c}\text { Chitosan } \\
\text { concentration } \\
(\% \text { mass })\end{array}\end{array}$ & $\begin{array}{c}(2) \\
\text { \%mass of } \\
\text { chitosan in } \\
\text { membrane } \\
\left(\mathrm{x}_{\mathrm{c}}\right)\end{array}$ & $\begin{array}{c}\text { Mean } \\
\text { density } \\
\left(\mathrm{kg} \cdot \mathrm{m}^{-3}\right)\end{array}$ & $\begin{array}{c}(4) \\
\text { Porosity } \\
(\varepsilon)\end{array}$ & $\begin{array}{c}(5) \\
\text { Pore radius } \\
(\mathrm{nm})\end{array}$ & $\begin{array}{c}\text { Specific } \\
\text { surface area } \\
\times 10^{5}\left(\mathrm{~m}^{2} \mathrm{~kg}^{-1}\right)\end{array}$ \\
\hline 2.0 & 2.2 & 1080 & 0.670 & 45.0 & \\
3.0 & 2.4 & 1088 & 0.660 & 43.5 & 1.192 \\
4.0 & 2.8 & 1090 & 0.665 & 43.0 & 1.190 \\
5.0 & 3.8 & 1100 & 0.650 & 42.5 & 1.185 \\
6.0 & 4.2 & 1091 & 0.650 & 41.0 & 1.180 \\
7.0 & 5.2 & 1098 & 0.648 & 40.0 & 1.176 \\
\hline
\end{tabular}

It can be seen that the porosity is only a slight function of the chitosan concentration and that its value is between 0.65 and 0.67 . It is found that as the chitosan casting solution concentration increases there is a slight decrease in the maximum pore radius (column 5). This could be attributed to the fact that more space is occupied by chitosan macromolecules when the chitosan content increased, resulting in a decreased pore radius. The maximum pore radius was found to be in the range of 40-45 nm, which correlates with the findings of Milot et al. [36], and is comparable to ultrafiltration (UF) membranes. The values of the relationship between the chitosan concentration and the specific surface area of the membrane on a dry basis is represented column 6 , wherein the trend of decreasing specific surface area with increasing chitosan solution concentration correlated with the trend observed with the total porosity (column 4), and the maximum pore radius (column 5). That is, an increase in the chitosan casting solution concentration lead to a lower total porosity and pore radii, which caused the total surface area to also decrease. This effect is somewhat dampened by the increase in the wet membrane density, since the specific surface area changed relatively little between a minimum of 1.175 and a maximum of $1.195 \times 10^{5} \mathrm{~m}^{2} \cdot \mathrm{kg}^{-1}$. 
SEM-micrographs of different membranes are shown in Figure 3, from which it is clear that a membrane prepared from a relative low chitosan concentration solution had a mechanically weak structure, i.e. sponge-like [Figure 3(a)]. It was further observed that as the membrane density increased with increasing chitosan concentration of the casting solution between 5.5 and 7.5 wt.\%, mechanically strong membranes were produced that had smooth and dense appearance as shown in Figure 3(b). At chitosan concentration of $8.0 \mathrm{wt} . \%$ and above, the membranes were characterised by surface cracks as shown in Figure 3(c). Permeation studies indicated that these membranes had very high fluxes (results not shown) compared with the membranes produced from casting solutions with lower chitosan concentrations, which suggested that the cracks observed on the membrane-surfaces represented significant micro defects. From these results it was concluded that mechanical strong, cohesive, and defect-free membrane was obtained using a chitosan casting solution containing between 5.5 and 7.5 wt.\% chitosan.

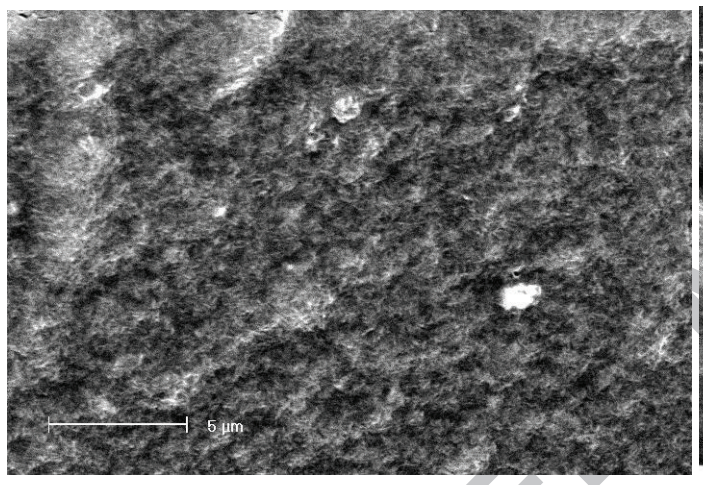

(a): $2.5 \operatorname{mass} \%$

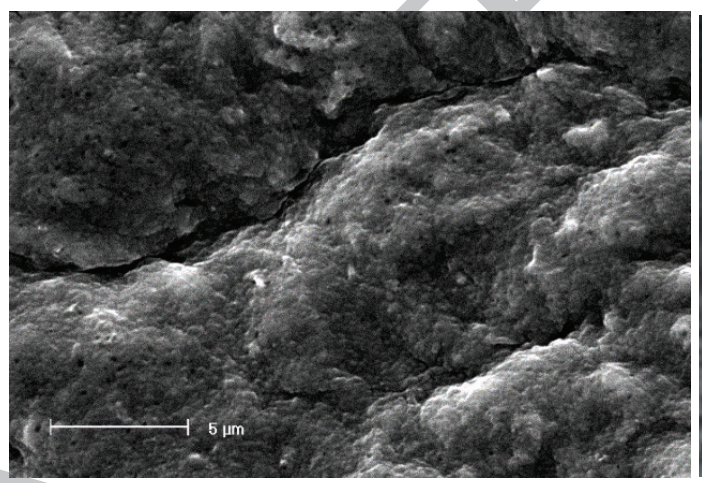

(c): $8.2 \operatorname{mass} \%$

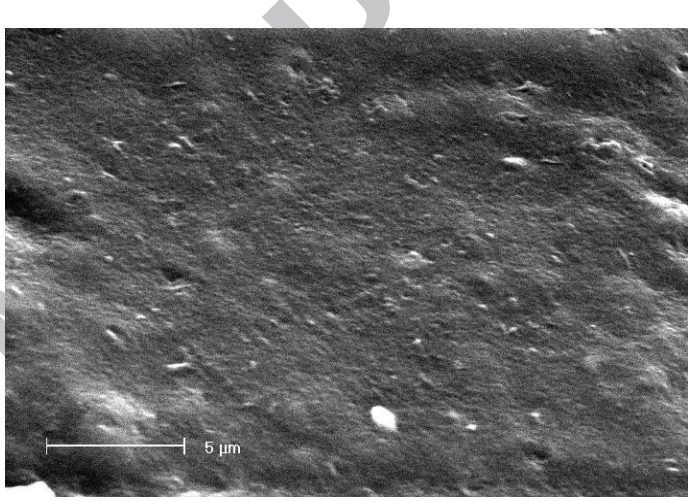

(b): $5.5 \operatorname{mass} \%$

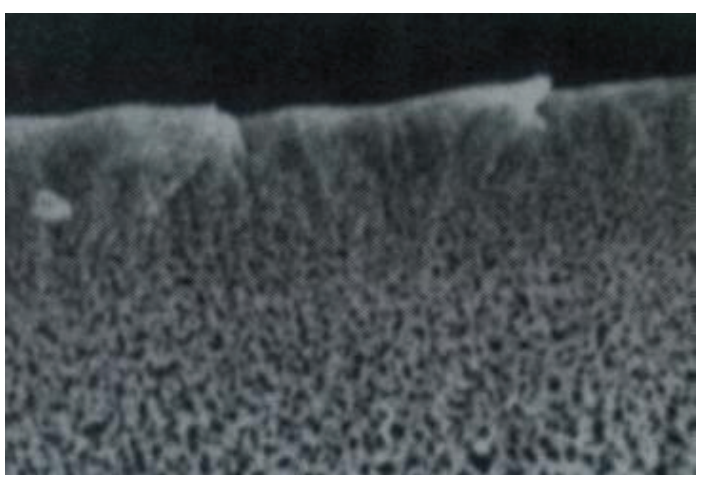

(d): cross section view

Figure 3: SEM analysis of chitosan membrane prepared from $4 \%$ acetic acid solution, at $25^{\circ} \mathrm{C}$ and from the following mass of chitosan: (a) $2.5 \%$ of chitosan, (b) $5.5 \%$ of chitosan, (c) $8.2 \%$ of chitosan and (d) cross section of chitosan membrane 
From the characterisation results, it was found that the membranes contained a large fraction of water (95 - 98 wt.\%), but that not all the water contained in the chitosan membranes synthesised in this study forms an integrated part of the membrane. Instead, water can be present as either free water, or as bound water. The water filling the macro-pores is termed free water, and the fixed water and the chitosan to which it is bound forms the rigid network of the membrane. When applying a pressure difference over the membrane, the free water can be transported through the porous network, while the fixed water remains bound to the chitosan, with the transport of free water through the membrane being similar to traditional MF and UF membranes. This transport mechanism corresponds with the cross-sectional SEM micrograph of a dehydrated (dry) membrane as shown in Figure 3(d), from which the honeycomb structure, or porous network, is apparent. It is also apparent from Figure 3(d) that the membrane is characterized by a denser top layer, suggesting that the chitosan membranes synthesized in this study are asymmetric, consisting of a porous sub-layer and a denser top layer.

A summary of the membrane properties of the chitosan membranes synthesised in this work is given in Table 3. The bubble point method showed that the maximum pore radius was found to be approximately $40 \mathrm{~nm}$, which classifies the chitosan membranes in the category of ultrafiltration (UF), in accordance with the classification given by Mulder [30]. Therefore, it can be concluded that the chitosan membranes synthesised in this study from a 7 wt.\% chitosan solution consisted of ca. 5 wt.\% chitosan, 30 wt. $\%$ fixed water and 65 wt. $\%$ free water. The characterisation data concerning the structure of the membranes further supports the proposed UF membrane structure. Although the presence of a dense skin-layer is visible from the cross-sectional SEM analysis, it is shown in the subsequent section that the transport properties of the chitosan membranes could be modelled with reasonable accuracy by assuming a porous membrane structure.

Table 3: Characteristics of the synthesised chitosan membranes.

\begin{tabular}{lcccc}
\hline \hline \multirow{2}{*}{ Characteristic } & \multicolumn{2}{c}{ Limits } & Optimum conditions & Units \\
\cline { 2 - 5 } & Min & Max & & \\
\hline Density & 1080 & 1100 & 1100 & $\mathrm{~kg} \cdot \mathrm{m}^{-3}$ \\
Chitosan in membrane & 2.2 & 5.2 & 5.2 & $\mathrm{mass} \%$ \\
Fraction free volume & 0.65 & 0.67 & 0.65 & $\mathrm{~kg} \cdot \mathrm{kg}^{-1}$ \\
Maximum pore radius & 40 & 45 & 40 & $\mathrm{~nm}$ \\
Total surface area & $1.18 \times 10^{5}$ & $1.2 \times 10^{5}$ & $1.18 \times 10^{5}$ & $\mathrm{~m}^{2} \cdot \mathrm{kg}^{-1}$ \\
\hline \hline
\end{tabular}

\subsection{Membrane transport characteristics}

The pure water permeation $\left(J_{P}\right)$ of a chitosan membrane is shown in Figure 4 as a function of the transmembrane pressure at a constant temperature of $298 \mathrm{~K}$. 


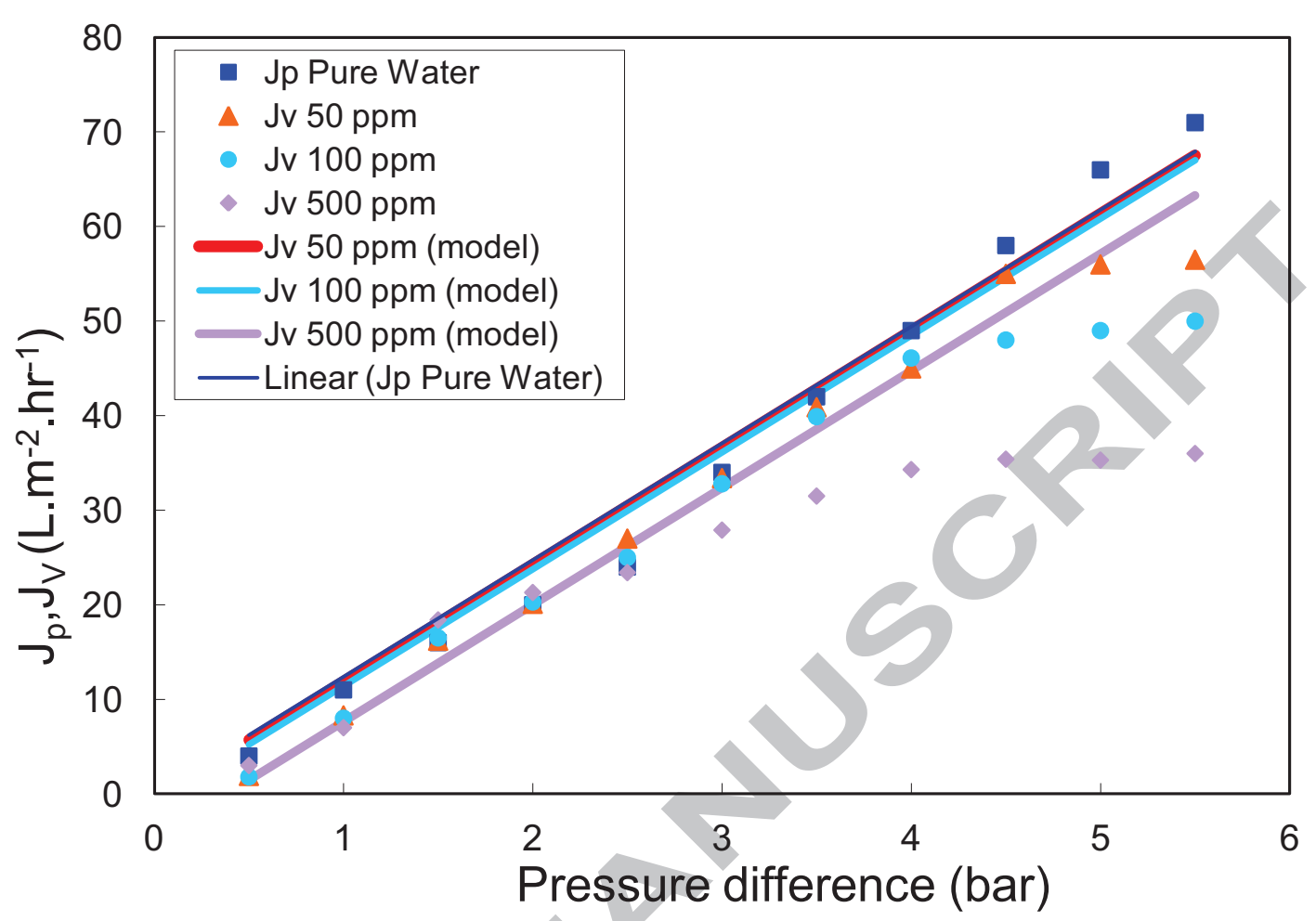

Figure 4: Pure water and solute fluxes as a function of pressure difference (membrane thickness $=0.8$ $\mathrm{mm}$ and $\mathrm{T}=298 \mathrm{~K}$ ), that indicates the limiting flux for each set of experimental conditions.

From the results presented in Figure 4, a permeability coefficient of $12.4 \mathrm{~L} \cdot \mathrm{m}^{-2} \cdot \mathrm{hr}^{-1} \cdot \mathrm{bar}^{-1}$ was determined from the slope, which lies within the range $\left(10-50 \mathrm{~L} \cdot \mathrm{m}^{-2} \cdot \mathrm{hr}^{-1} \cdot \mathrm{bar}^{-1}\right)$ of ultrafiltration, pressure driven membrane processes. Both the Kozeny-Carman equation [(Eq. (5)] and the Hagen-Poiseuille equation [(Eq. (6)] were also applied, using a porosity of 0.65 , a total surface area of $1.2 \times 10^{5} \mathrm{~m}^{2} \cdot \mathrm{kg}^{-1}$ and a permeability coefficient of 12.4 L.m $\mathrm{m}^{-2} \cdot \mathrm{hr}^{-1} \cdot \mathrm{bar}^{-1}$ as determined from the results of Figure 5. Subsequently, the K-value of the Kozeny-Carman equation was calculated to be 4.83, which compares well with a value of $\mathrm{K}=5$ that is conventionally used for micro- and ultrafiltration processes [31]. Accordingly, the average pore radius was calculated to be $23 \mathrm{~nm}$ using the Hagen-Poiseuille equation by assuming that the tortuosity is equal to the reciprocal porosity [35]. Although the pore size distribution could not also be determined, the average pore radius value of $23 \mathrm{~nm}$ correlated well with the maximum pore radius of $40 \mathrm{~nm}$ as found from the bubble-point experiments, and confirms that the effective pore size of the chitosan membrane falls within that of UF membranes (Table 2). 
The solute permeability $(\omega)$ and the reflection coefficient $(\sigma)$ was determined by performing flux measurements at varying pressures using a salt solution. By measuring the solvent flux $\left(J_{v}\right)$ and the solute flux $\left(J_{S}\right)$, and applying van't Holf's Law where the osmotic pressure difference across the membrane is related to the concentration difference of a dilute solution as $\Delta \pi=\Delta C$. The two parameters ( $\omega$ and $\sigma$ ) was calculated from the linearized form of Eq. (8) as shown in Eq. (12):

$$
\frac{J_{S}}{\Delta c}=(1-\sigma) \cdot J_{V} \cdot \frac{c_{S}}{\Delta c}+\omega
$$

In other words, the reflection $(\sigma)$ and solute permeability $(\omega)$ could be determined from the slope of a plot of $\frac{J_{S}}{\Delta c}$ vs. $\frac{J_{V} \cdot c_{S}}{\Delta c}$, as shown in Figure 5.

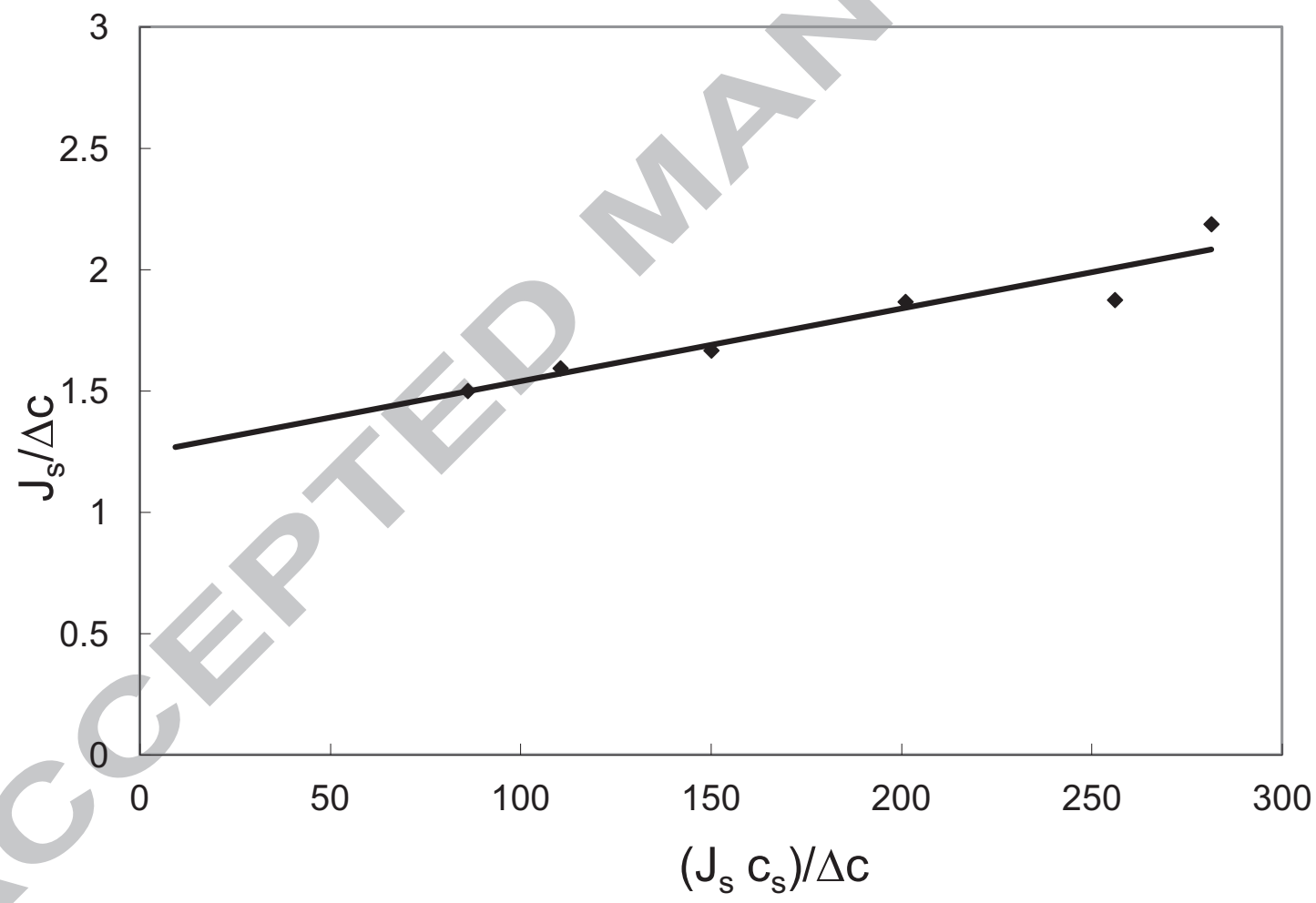

Figure 5: Determination of the solute permeability coefficient and the reflection coefficient, with solution concentration of $\mathrm{C}=50 \mathrm{mg} \cdot \mathrm{L}^{-1}$, at $25^{\circ} \mathrm{C}$. 
The results presented in Figure 5 correspond with a feed solution concentration of a $50 \mathrm{mg} . \mathrm{L}^{-}$ ${ }^{1} \mathrm{ZnSO}_{4} \cdot 7 \mathrm{H}_{2} \mathrm{O}$ solution, from which the transport parameters were determined as $\sigma=0.997$ and $\omega=1.24 \mathrm{mg} \cdot \mathrm{m}^{-2} \cdot \mathrm{hr}^{-1} \cdot \mathrm{bar}^{-1}$. The relatively low solution concentration of $50 \mathrm{mg} \cdot \mathrm{L}^{-1}$ was used for these experiments to minimise the effects of concentration polarisation. The high reflection coefficient at the membrane can be attributed to the adsorption of zinc ions since chitosan has the characteristics of adsorbing metal ions, hence the low solute permeability coefficient.

Experiments with higher solute concentrations, where the volumetric flow rate of the solvent was determined as a function of the pressure difference, while also varying the solute concentrations, were also performed. The solvent flux was modelled using the thermodynamic model given by in Eqs. (7) and (8) together with the solvent permeability coefficient and the solute permeability and retention coefficient as determined from the results presented in the preceding section. The solvent flux results are also given in Figure 4. It can be deduced from Figure 4 that the volumetric flow rate of the solvent in the solution is well predicted by the thermodynamic model at low pressure differences, but deviates to higher fluxes at higher pressure differences. From the results, concentration polarization is more pronounced at $500 \mathrm{mg} . \mathrm{L}^{-1}$ than at $50 \mathrm{mg} . \mathrm{L}^{-1}$, as is evident by the decrease in flux with increasing transmembrane pressure at $\Delta \mathrm{P}$-values higher than ca. 3 bar. The solvent flow rate increases linearly with transmembrane pressure at low $\Delta \mathrm{P}$-values, and reaches a maximum value at higher $\Delta \mathrm{P}$-values. At the point where the maximum solvent flux is reached, the transport is mainly controlled by the concentration polarisation effect. This maximum observed permeability is termed the limiting flux $\left(\mathrm{J}_{\mathrm{Vlim}}\right)$ and is a function of the solute concentration as is also evident from Figure 4.

The limiting flux depends on the concentration in the bulk of the feed $\left(\mathrm{c}_{\mathrm{in}}\right)$, the concentration at the membrane interface $\left(\mathrm{c}_{\mathrm{m}}\right)$ and the aqueous-phase mass transfer coefficient of the solute (k) according to Eq. (11). In Figure 6, the limiting flux is plotted against the logarithm of the bulk solute concentration [Eq. (10)]), based on the data presented in Figure 4, as well as data obtained at various other concentration values between 10 and $500 \mathrm{ppm} \mathrm{Zn}$ (II) that are not included in Figure 4. Consequently, the mass transfer coefficient and the natural logarithm of the membrane interface concentration can be obtained from the slope and intercept respectively (Figure 6), which yielded a value of $9.0 \mathrm{Lm}^{-2} \mathrm{hr}^{-1}\left(2.5 \cdot 10^{-6} \mathrm{~m} . \mathrm{s}^{-1}\right)$ for the external mass transfer coefficient was determined, which is typical for electrolyte systems. The membrane interface concentration was determined to be $28 \cdot 10^{3} \mathrm{mgL}^{-1}$. Concentration 
polarisation is normally severe in ultrafiltration processes due to the high solvent flux afforded by the membrane relative to that of the solute. This relatively high interface concentration could possibly be due to $\mathrm{Zn}$ (II) adsorption by the membrane.

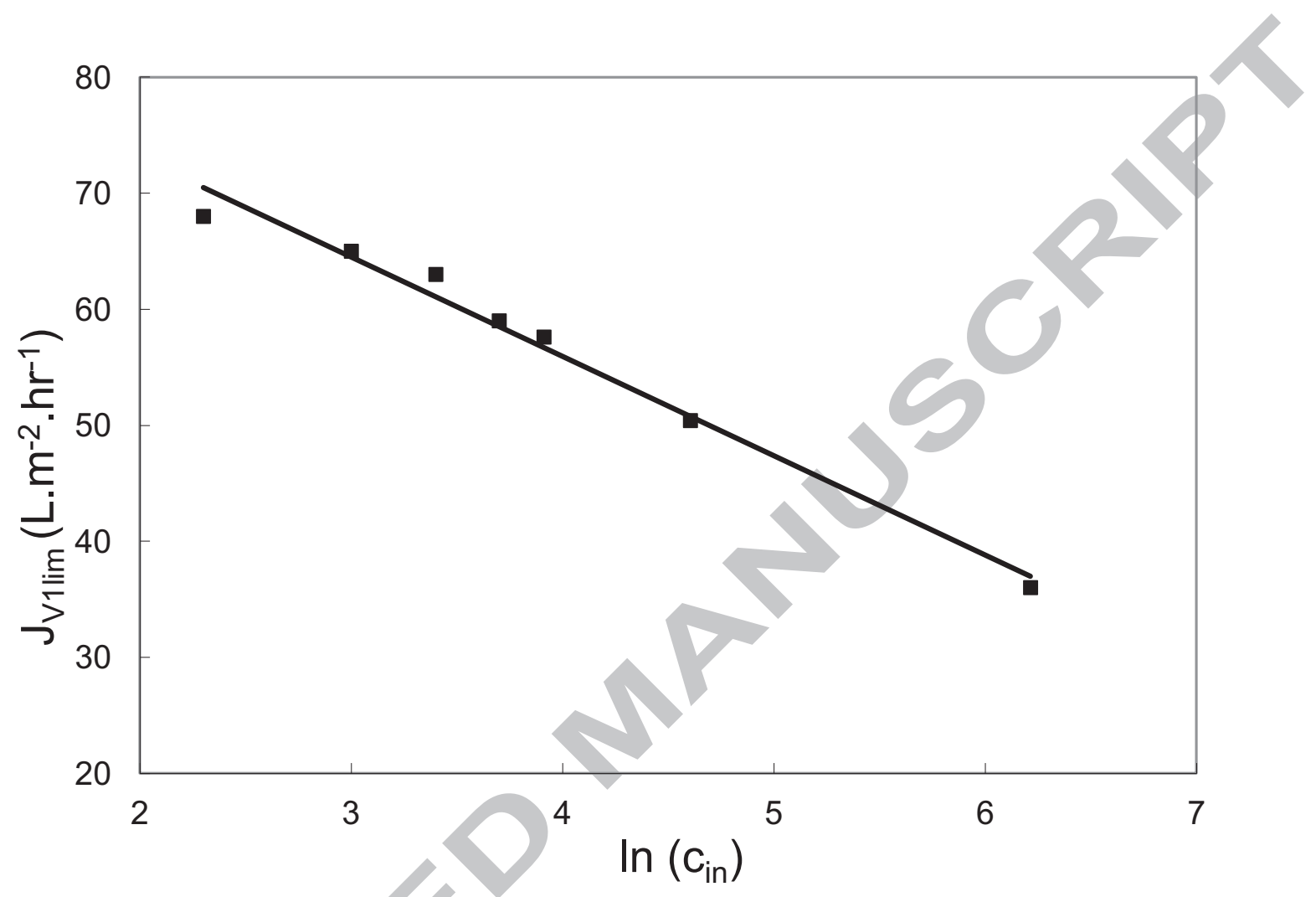

Figure 6: Limiting permeation plotted as a function of the logarithm of the bulk concentration $($ Pressure difference $=100 \mathrm{kPa})$. 


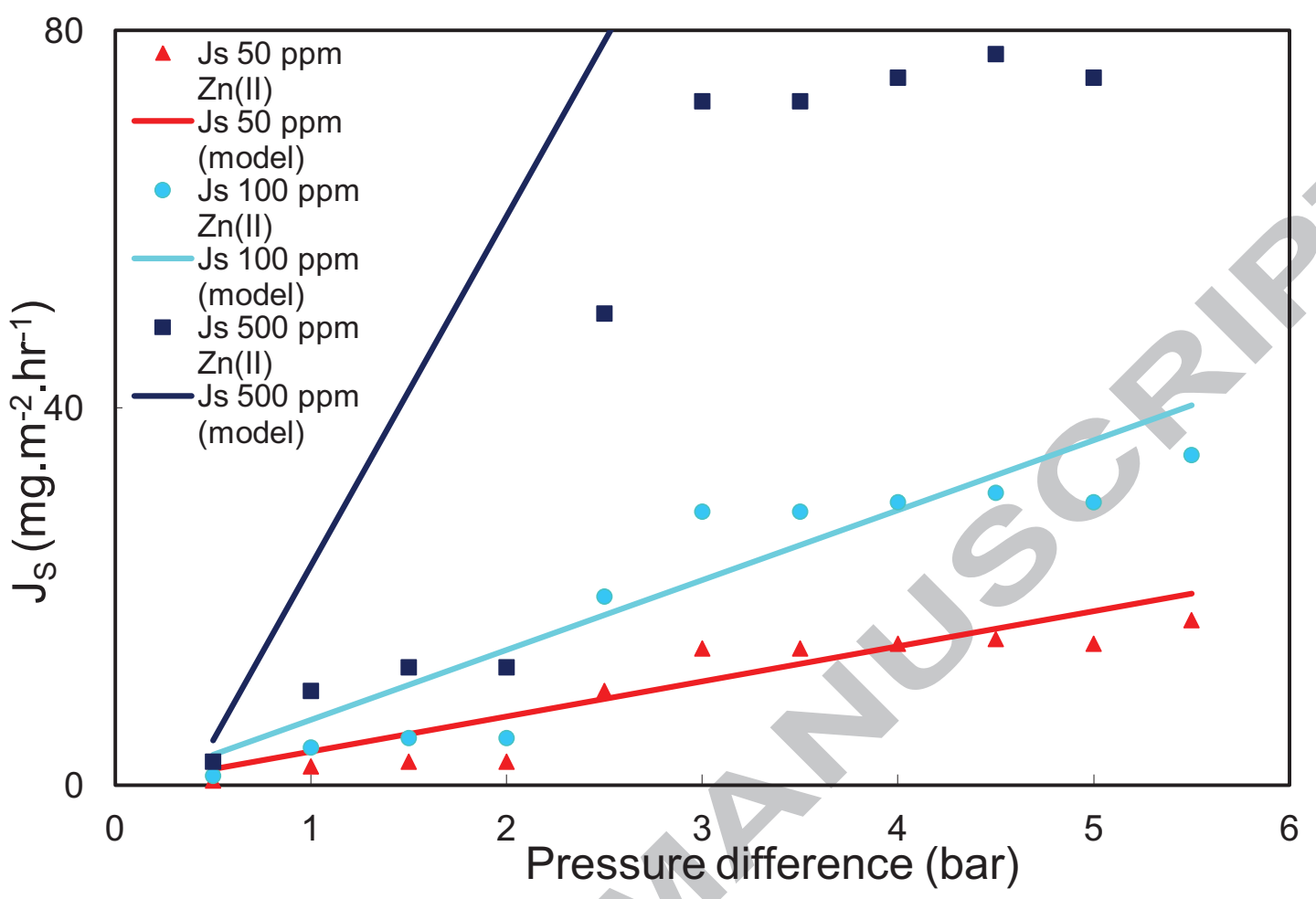

Figure 7: Solute flux as a function of pressure difference and solute concentration (membrane thickness $=0.8 \mathrm{~mm}$ and $\mathrm{T}=298 \mathrm{~K})$.

In addition, the solute permeability was measured as a function of the applied transmembrane pressure for varying solute concentrations, of which the results are shown in Figure 7. The experimental data points are represented by the points and the model fits [Eqs. (7) and (8)] are given by the straight lines. The solute flux is accurately predicted at low solute concentrations (50 and $100 \mathrm{ppm}$ ), but are overestimated at the maximum concentration of $500 \mathrm{ppm}$ that was used in this study. This could be attributed to concentration polarisation effects that are not well accounted for in the present model.

The effect of membrane thickness on the solvent flux using a $50 \mathrm{mg} . \mathrm{L}^{-1}$ zinc solution was also investigated, and the results are shown in Figure 8. As expected, an increase in membrane thickness results in a decrease in flux. The effect of membrane thickness was evaluated using the thermodynamic model as described by Eqs. (5) and (6), and the experimentally determined permeability coefficient. 


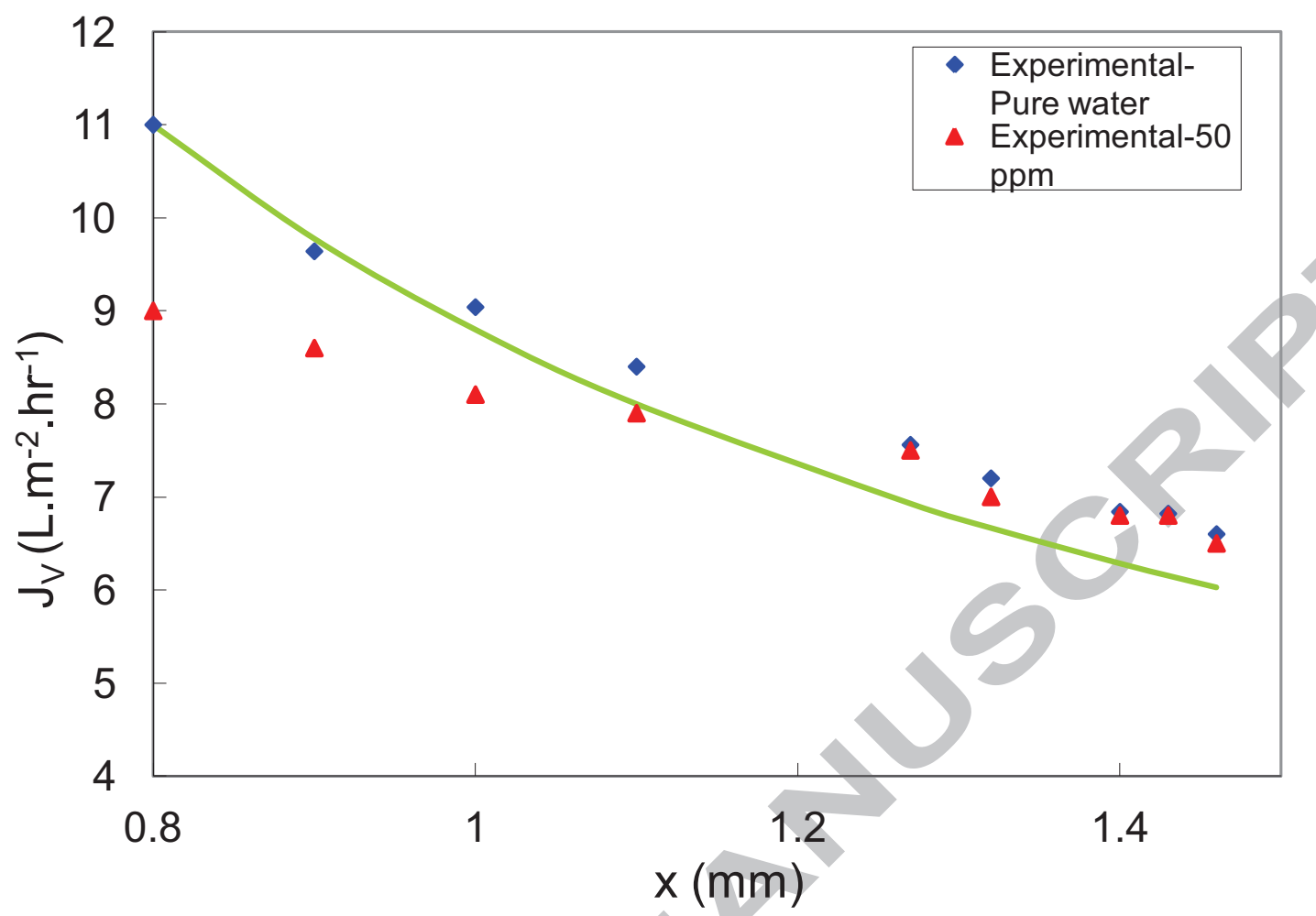

Figure 8: The relationship between solvent flux and membrane thickness (Pressure difference $=100 \mathrm{kPa})$.

As is clear from the results presented in Figure 8, the experimental solvent flux values are reasonably well correlated at membrane thicknesses close to $0.8 \mathrm{~mm}$. At thicknesses above $1.1 \mathrm{~mm}$, the model underestimates the solvent flux. This could be a result of the preparation method that was used, i.e. that the same crosslinking time was used, independent of the membrane thickness. This could have resulted in the thicker membranes being relatively more porous than the thinner membranes, subsequently improving the permeation properties. A zinc salt solution, containing $500 \mathrm{mgL}^{-1} \mathrm{Zn}^{2+}$ was prepared and the $\mathrm{pH}$ of the solution was varied using sulphuric acid to obtain acidic solutions, while sodium hydroxide was used to obtain alkaline solutions. The flux was determined using a $0.8 \mathrm{~mm}$ thick membrane. The results are shown in Figure 9, wherein the transmembrane pressure and temperature were kept constant at $100 \mathrm{kPa}$ and $298 \mathrm{~K}$ respectively. 


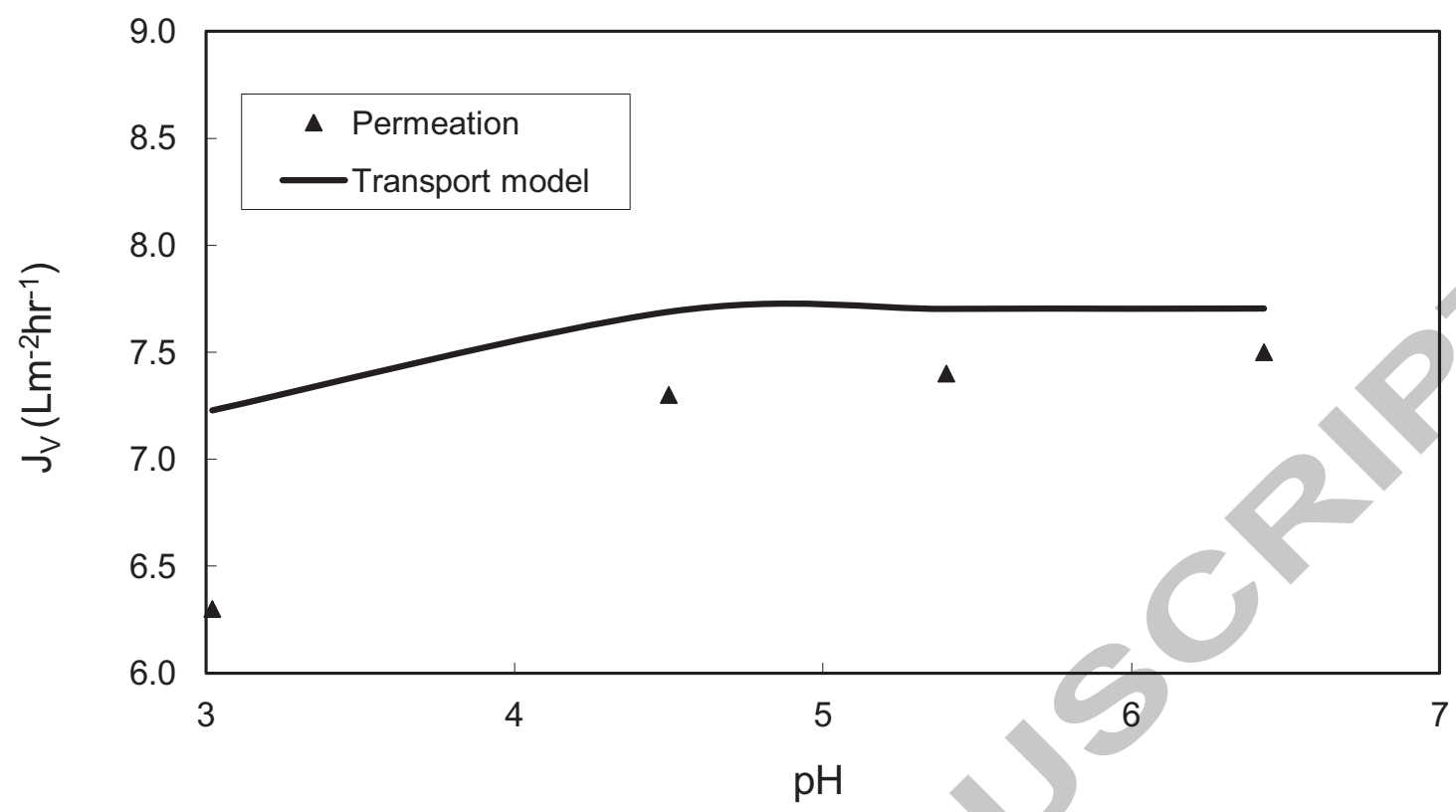

Figure 9: Effect of $\mathrm{pH}$ on membrane permeability, modelled by the osmotic model (Membrane thickness $=0.8 \mathrm{~mm}$, and $500 \mathrm{ppm} \mathrm{Zn}$ with $100 \mathrm{kPa}$ at room temperature).

At low $\mathrm{pH}$, the osmotic pressure of the solution is relatively high compared to the applied membrane pressure difference (40 $\mathrm{kPa}$ compared to $100 \mathrm{kPa}$ ). At sufficiently low osmotic pressures (above $\mathrm{pH}=4$ ), the permeability remains constant with increasing $\mathrm{pH}$. It can therefore be concluded that within the workable adsorption $\mathrm{pH}$ range (efficient adsorption between 4 and 7), the $\mathrm{pH}$ has no significant effect on the permeability. The effect was modelled in Figure 9 using the transport model of Eq. (7), and a slight deviation between the model and experimental results were observed.

A zinc salt solution, containing $500 \mathrm{mgl}^{-1} \mathrm{Zn}^{2+}$ was prepared and used as feed to the membrane assembly, while the temperature of the solution was varied. The flux was determined using a $0.8 \mathrm{~mm}$ thick membrane, and the transmembrane pressure was kept constant at $100 \mathrm{kPa}$. The effect of temperature on the solvent flux of the membrane is shown in Figure 10, from which it is clear that the solvent flux increases slightly with increasing temperature, which could simply be due to a decrease in the viscosity of the solution. It is also apparent that the osmotic pressure model provides a reasonably accurate description of the data. 


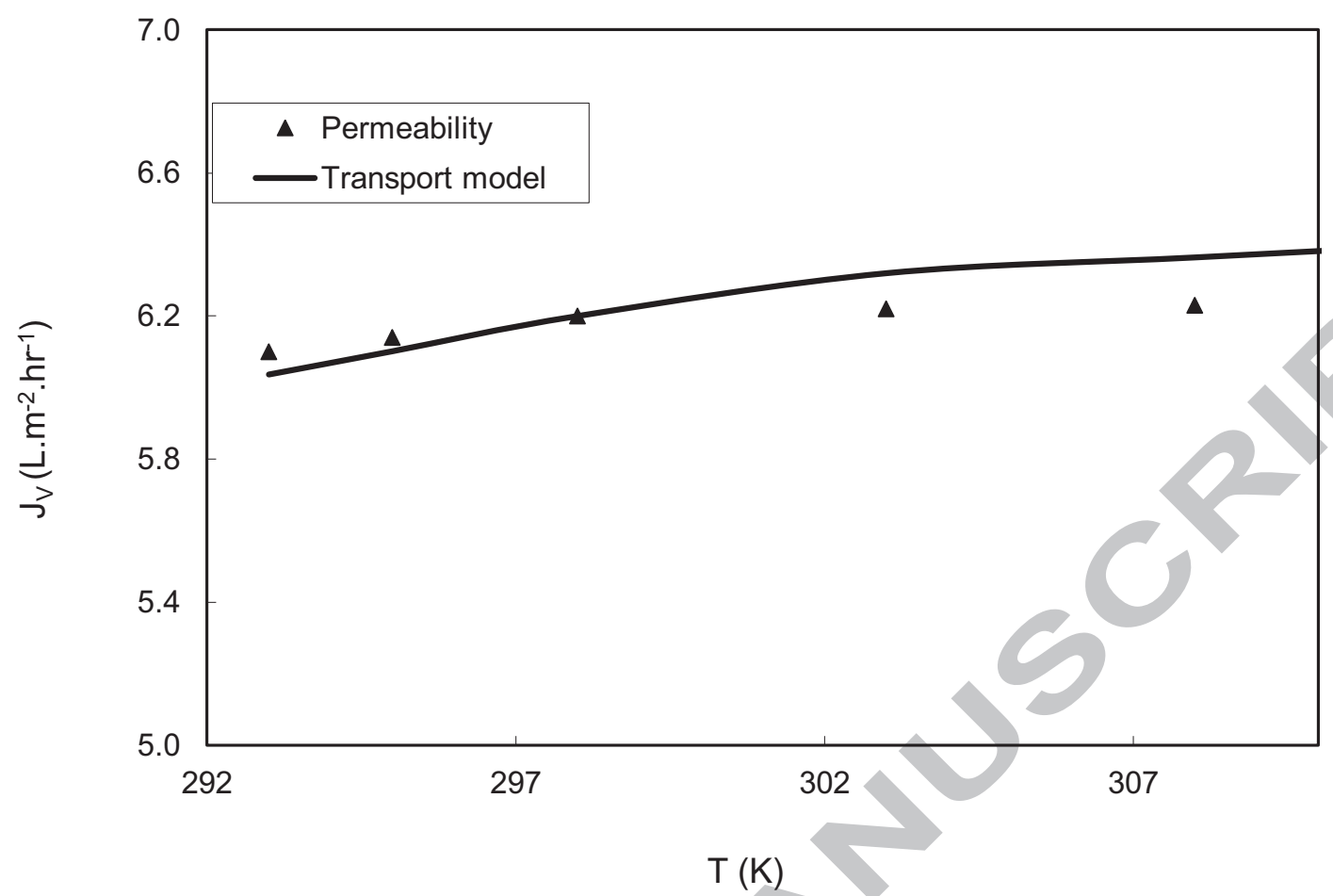

Figure 10: The relationship between permeability and temperature and is modelled by the transport model (Membrane thickness $=0.8 \mathrm{~mm}$, and $500 \mathrm{ppm} \mathrm{Zn} \mathrm{with} 100 \mathrm{kPa}$ pressure difference).

\section{Conclusions}

It was found that the chitosan-acetic acid solution viscosity is an important parameter in the manufacture of mechanically strong chitosan membranes that exhibit desirable transport and adsorption characteristics. The molecular weight of the chitosan specimen was also found to influence the viscosity of the chitosan-acetic acid casting solution, where a higher viscosity of the chitosan-acetic acid solution was obtained at higher molecular weights. The effect of the degree of deacetylation on the viscosity was however found not to be significant. The effect of the membrane production parameters (chitosan- and acetic acid concentration) on the viscosity was found to be determined mainly by the chitosan concentration. It was subsequently found that higher chitosan concentrations lead to a higher membrane density, a decreased pore size, membrane water content, and specific surface area.

A transport model, based on irreversible thermodynamics, with incorporation of an experimentally determined water permeability coefficient of $12.4 \mathrm{~L} \cdot \mathrm{m}^{-2} \cdot \mathrm{hr}^{-1} \cdot \mathrm{bar}^{-1}$, solute permeability of $1.24 \mathrm{mg} \cdot \mathrm{m}^{-2} \cdot \mathrm{hr}^{-1} \cdot \mathrm{bar}^{-1}$; and a reflection coefficient of 0.997 , was shown to 
accurately described the transport of solvent and solute through the chitosan membranes at low solute concentrations. At high solute concentrations, the model deviates from the experimental values, mainly due to the occurrence of concentration polarisation. The effect of $\mathrm{pH}$ and temperature on the solvent flux was found to be fairly accurately described using this model.

From both the structural and transport properties, it can be concluded that the synthesised chitosan membranes could be modelled as ultrafiltration (UF) membranes with capillary pores. By modelling the transport of water through the membranes using the HagenPoiseuille equation, an average pore radius of $23 \mathrm{~nm}$ was determined, and a K-value of 4.83 was found when using the Kozeny-Carman equation.

\section{Acknowledgements}

The authors wish to thank the Water Research Commission, South Africa for its financial support and Dr Sam Erevbenagie Usadolo for editorial assistance.

\section{References}

[1] Igberase E, Osifo P. Equilibrium, kinetic, thermodynamic and desorption studies of cadmium and lead by polyaniline grafted cross-linked chitosan beads from aqueous $J$. Ind. Eng. Chem. 26 (2015) 340-347.

[2] Babel S, Kurniawan TA. Low-cost adsorbents for heavy metals uptake from contaminated water: a review. J. Hazard. Mater. (2003) B97, 219-243.

[3] Abou El-Reash YG, Abdelghany AM, Elrazak AA. Removal and Separation of $\mathrm{Cu}(\mathrm{II})$ from Aqueous Solutions Using Nano-Silver Chitosan/Polyacrylamide Membranes, Int. J. Biol. Macromol. 86 (2016) 789-798.

[4] Guibal E, Milot C, Roussy J. Influence of Hydrolysis Mechanisms on Molybdate Sorption Isotherms Using Chitosan. Int. J. Biol. Macromol. (1999)1-26.

[5] Zhao F, Repo E, Yin D, Sillanpaa, MET. Adsorption of Cd(II) and Pd(II) by a novel EGTAmodified chitosan material: Kinetics and isotherms, J. Colloid Interface Sci. 409 (2013) 174182.

[6] Yu Q, Kaewsarn P. Binary adsorption of copper(II) and cadmium(II) from aqueous solutions by biomass of marine alga Durvillaea Potatorum. Sep. Sci. Technol. 34 (1999) 1595-1605. 
[7] Dastgheib SA, Rockstraw DA. Systematic study and proposed model of the adsorption of binary metal ion solutes in aqueous solution onto activated carbon produced from pecan shells. Carbon, 11 (2002) 1853-1861.

[8] Vaughan T, Seo CW, Marshall W. Removal of selected metal ions from aqueous solution using modified corncobs. Bioresour. Technol. 78 (2001) 133-139.

[9] Huang $\mathrm{C}$, Chung $\mathrm{Y}$, Liou M. Adsorption of $\mathrm{Cu}(\mathrm{II})$ and $\mathrm{Ni}(\mathrm{II})$ by pelletized biopolymer. $J$. Hazard. Mater. 45 (1996) 265-277.

[10] Guibal E, Milot C, Eterradossi O, Gauffier C, Domard A. Study of molybdate ion sorption on chitosan gel beads by different spectrometric analyses. Int. J. Biol. Macromol. 24 (1999) 49$\underline{59 .}$

[11] Krajewska B. Pore structure of gel chitosan membranes. III. Pressure-driven mass transport measurements. Polym. Gels and Networks. 4 (1996) 55-63.

[12] Kurniawan TA, Chan GYS, Lo W, Babel S. Physico-chemical treatment techniques for wastewater laden with heavy metals. Chem. Eng. J. 118 (2006) 83-98.

[13] Muzzarelli RAA. Natural chelating polymers: Alginic acid, chitin and chitosan. Oxford: Pergamon press (1977).

[14] Wu C, Tian J, Li S, Wu T, Hu Y, Chen S, Sugawara T, Ye X. Structural properties of firms and rheology of firm-forming solutions of chitosan gallate for food packaging. Carbonhydr. Polym. (2016) In Press.

[15] No HK, Meyer SP. Preparation of chitin and chitosan. Chitin Hand Book. Edited by Muzzarilli, RAA and Peter, MG. European Chitin Society. (1997) 475-489.

[16] Snyman D, Hamman JH, Kotze JS, Rollings JE, Kotze AF. The relationship between the absolute molecular weight and the degree of quanternisation of $N$-trimethy chitosan chloride. Carbohydr. Polym. 50 (2002) 145-150.

[17] Roberts GAF. Determination of degree of N-acetylation of chitin and chitosan. Chitin Handbook. Edited by: Muzzarelli RAA and Peter MG; European Chitin Society (1997) 129136.

[18] Kumar R, Isloor AM, Ismail AF. Preparation and evaluation of heavy metal rejection properties of polysulfone/chitosan, polysulfone/N-succinyl chitosan and polysulfone $/ \mathrm{N}$ propylphosphonyl chitosan blend ultrafiltration membranes.

[19] Young RJ. Introduction to polymers. New York: Chapman and Hall. (1980) 331.

[20] Kaminski W, Modrzejewska Z. Application of Chitosan Membranes in Separation of Heavy Metal Ions. Sep. Sci. Technol. 32 (1997) 2659-2668.

[21] Guibal E. Interaction of metal ions with chitosan-based sorbents: a review. Sep. Pur. Technol. 38 (2004) 43-74. 
[22] Kawamura Y, Yoshida H, Asai S. Effects of Chitosan Concentration and Precipitation Bath Concentration on the Material Properties of Porous Cross-linked Chitosan Beads. Sep. Sci. Technol. 32(1997) 1959-1974.

[23] Osifo PO, Webster A, Van Der Merwer H, Neomagus HWJP, Van Der Gun MA, Grant DM. The influence of the degree of cross-linking on the adsorption properties of chitosan beads. Bioresour. Technol. 99 (2008) 7377-7382.

[24] Pellegrin B, Mazzari F, Hanafi Y, Szymcyk A, Rmigy J-C, Causserand C. Filtration performance and pre size distribution of hypochlorite aged PES/PVP ultrafiltration membranes. J. Membr. Science. 474 (2014) 175-186.

[25] Pawlowski BS. Determination of the iodine number of activated carbon. (Paper as part of analytical manual for SATECH.) Sasolburg. (1971) 23. (Unpublished)

[26] Osifo PO, Masala A. Characterization of direct methanol fuel cell (DMFC) applications with

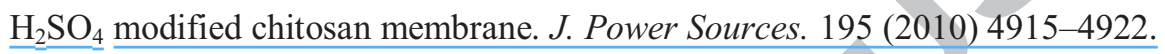

[27] Krajewska B. Diffusion of metal ions through gel chitosan membranes. React. Funct. Polym. 47 (2001) 37-47.

[28] Taoualit $\mathrm{N}$, Hadj-Boussaad DE. Metallic species $\left(\mathrm{Ag}^{ \pm} \underline{\text { and } \mathrm{Cu}^{2+}} \underline{\text { ions) transfer through a }}\right.$ membrane-gel. Desalination. 144 (2002) 273-277.

[29] Peppas NA, Reinhart CT. 1983. Solute diffusion in swollen membranes. J. Membr. Science. 15 (1998) 275.

[30] Mulder M. Basic Principles of Membrane Technology. $2^{\text {nd }}$ ed. The Netherlands: Kluwer Academic Publishers. (1998) 564.

[31] Davies L, Dollimore D. Theoretical and experimental values for the parameter $\mathrm{k}$ of the Kozeny-Carman equation, as applied to sedimenting suspensions. J. Physics. 13 (1980) 2013-2020.

[32] Lakshminarayanaiah I. Transport phenomena in membranes. Academic Press, Orlando, USA. (1969) 300.

[33] CUSSLER, E.L., 1997. Diffusion: mass transfer in fluid systems, Cambridge University Press, Cambridge University Press, 17 - 33.

[34] Chong TH, Wong FS, Fane AG. The effect of imposed flux on biofouling in reverse osmosis: Role of concentration polarisation and biofilm enhanced pressure phenomena. J. Membr. Science. 325 (2008) 840-850.

[35] Neomagus HWJP, Van Swaaij WPM, Versteeg GF. The catalytic oxidation of $\mathrm{H}_{2} \mathrm{~S}$ in a stainless steel membrane reactor with separate feed of reactants. J. Membr. Science. 148 (1998) $147-160$. 